NBER WORKING PAPER SERIES

\title{
DIRECT TO CONSUMER ADVERTISING OF PHARMACEUTICAL DRUGS: INFORMATION AND PERSUASION
}

\author{
Talia Bar \\ Dean R. Lillard \\ Working Paper 19794 \\ http://www.nber.org/papers/w19794 \\ NATIONAL BUREAU OF ECONOMIC RESEARCH \\ 1050 Massachusetts Avenue \\ Cambridge, MA 02138 \\ January 2014
}

The views expressed herein are those of the authors and do not necessarily reflect the views of the National Bureau of Economic Research.

NBER working papers are circulated for discussion and comment purposes. They have not been peerreviewed or been subject to the review by the NBER Board of Directors that accompanies official NBER publications.

(C) 2014 by Talia Bar and Dean R. Lillard. All rights reserved. Short sections of text, not to exceed two paragraphs, may be quoted without explicit permission provided that full credit, including $\odot$ notice, is given to the source. 
Direct to Consumer Advertising of Pharmaceutical Drugs: Information and Persuasion

Talia Bar and Dean R. Lillard

NBER Working Paper No. 19794

January 2014

JEL No. I18,L15,L65,M37

\begin{abstract}
$\underline{\text { ABSTRACT }}$
We formally model direct to consumer advertising (DTCA) of prescription drugs and examine factors that determine a pharmaceutical firm's DTCA strategy. We highlight how the profitability of DTCA varies with the characteristics of the condition that the advertised drug treats, the incidence of the condition, land the signal value of symptoms, and risk factors. We account for the potential information benefits Ifrom DTCA as well as its potential to persuade consumers. From a welfare perspective there can beltoo much or too little private investment in advertising. Welfare is more likely to increase when the[population is uninsured.
\end{abstract}

Talia Bar

Department of Economics

University of Connecticut

365 Fairfield Way Unit 1063

Storrs, CT 06269-1063

talia.bar@uconn.edu

Dean R. Lillard

Department of Human Sciences

The Ohio State University

1787 Neil Avenue

Columbus, OH 43210

and NBER

lillard.13@osu.edu 


\section{Introduction}

Spending on direct to consumer advertising (DTCA) of prescription drugs has risen sharply over the past twenty years. Annual expenditures for television advertising have increased from around 400 million dollars in 1986 to a peak of around 5.4 billion in 2006. Since then, it has declined to roughly 3.5 billion dollars in 2012 (Pharma Marketing 2013). DTCA remains a subject of controversy and intense policy debates, in part because of its potential to broadly affect behavior in ways that are still not fully understood. Much of the extant research is empirical. Our paper theoretically models a pharmaceutical firm's choice of DTCA spending, and the effects of DTCA on consumers' behavior, and on social welfare. Our model highlights some of the special features of advertising in the pharmaceutical industry.

The economics literature differentiates between informative and a persuasive advertising. For drugs, advertising likely plays both roles. Drug advertising informs if, after seeing it, more consumers know about a health condition and the available treatments; it persuades if it causes consumers to believe they will enjoy a higher than the true benefit from the advertised drug.

An important way in which DTCA of drugs differs from advertising of other goods is that physicians play an important role in determining demand for drugs, particularly prescription drugs. To keep a body healthy one sometimes requires specialized knowledge. Because this knowledge is costly to get, consumers have incentives to hire an agent, the 
physician, who has the knowledge to diagnose conditions that cause poor health and to prescribe effective treatments. In the case of advertising of a prescription drug, information does not lead the consumer directly to the purchase of the drug but rather to visit a doctor who provides information that consumers (potentially) use to choose an alternative treatment. Even if DTCA persuades consumers to want the drug, the doctor does not necessarily prescribe it. Our analysis of DTCA accounts for both consumer behavior and physicians' prescribing practices.

The profitability of DTCA of a drug depends on characteristics of the condition it treats. First, the prevalence of the condition matters. Second, a consumer's expected benefit from treatment depends on the nature and severity of the symptoms or risk factors associated with the particular condition. ${ }^{1}$ When healthy people are less likely to have the symptoms or risk factors associated with the condition the advertised drug treats, the presence of symptoms more clearly signal that a person needs treatment. We show that expenditure on direct to consumer advertising is higher when the prevalence of the condition is high and when signals are more informative in the above sense.

We consider the welfare implications of DTCA. When advertising informs, it may reduce the extent to which people with given conditions go untreated. In doing so, informative advertising can enhance welfare. If advertising persuades, it can distort what people perceive as best for them and lead them to choose treatments that are either ineffective or that

\footnotetext{
${ }^{1}$ Evidence in Iizuka (2004) suggests that firms are more likely to advertise drugs that the FDA rates as a high priority and in markets where target conditions are more prevalent.
} 
waste resources. This could lead to a welfare loss. At the same time, persuasive advertising might improve welfare if it gets sick consumers to seek medical care. In some cases, the advertising for one drug may persuade consumers to seek medical care, even though they will receive a different more suitable treatment. Donohue et al. (2004) present evidence suggestion that DTCA of anti-depressant drugs increases the number of people who are diagnosed with depression and who began treatment with medication, and some evidence of an increase in the number of patients who received the medically appropriate duration of treatment. Among the population at any given time, some consumers are sick but do not seek medical care. If the price consumers pay for the drug and for doctor visits exceeds the marginal cost, then too few consumers get treated compared to the social optimum. In this case, persuasive advertising can enhance welfare if it induces those consumers to seek care. This positive effect of DTCA on welfare is more likely when consumers do not have health insurance and when doctors reliably serve their role as gatekeepers. While less evidence is available to test whether DTCA induces new doctor visits, available evidence suggests that DTCA improves some treatment outcomes. Bradford et al. (2010) find that patients exposed to higher DTCA more rapidly adopt an advertised treatment when they are better clinical candidates for that pharmaceutical treatment. And patients whose clinical profile recommends against being prescribed the treatment are less likely to get that treatment in areas with higher DTCA for the drug. On the other hand, we argue that when the population has health insurance, and consumers do not account for the full social cost of the drug and doctor visit, then DTCA is more likely to be excessive from a social point of 
view.

Theoretical models of DTCA are sparse. A notable exception is Brekke and Kuhns (2006) who focus on informative advertising and the complementarity between DTCA and money spent on marketing of drugs directly to physicians (known as "detailing"). Existing empirical studies find that DTCA raises sales in a therapeutic drug class but not market share of particular advertised anti-depressant medications (Rosenthal et al., 2003), statins (Wosinska, 2005), and antihistamines (Iizuka and Jin, 2007). These findings may be consistent with an informative view because advertising informs previously undiagnosed consumers about a health condition and the availability of treatments. Iizuka (2004) finds that new drugs and drugs for under-treated diseases are more frequently advertised. More direct survey data also suggests that DTCA informs. Two studies (Aikin et al., 2004 and Weissman et al., 2004) surveyed physicians to document whether doctors perceived their patients to be demanding more information in the period that DTCA was increasing. According to these studies 71 percent of doctors reported increases in the number of patients who were gathering information about prescription drugs. There is also some empirical evidence that advertising might persuade. Weissman et al. (2004) find that $18 \%$ of physicians surveyed perceived DTCA to have caused problems in their doctor-patient interactions. Of these physicians, $41 \%$ spent time correcting misconceptions; $78.6 \%$ thought DTCA encouraged (patients to request) unnecessary treatment; $26 \%$ thought DTCA caused their patients to ask for an inappropriate drug. These results may not contradict the evidence of the informative nature of DTCA, because even if DTCA persuades, a particular adver- 
tised drug is not necessarily prescribed in part because doctors act as gatekeepers between consumers and firms. Bradford and Kleit (2011) find that advertising reduces switching between brands, leads consumers to continue to use the drugs, and that consumers do respond to credible information in advertisements - in the form of Food and Drug Administration warnings. So, available evidence supports the hypothesis that both effects operate.

In this paper we model DTCA as both informative and persuasive, thus accounting for both roles established in the previous literature. Section 2 presents the model in particular, our assumptions on the health condition and treatments, on individuals, doctors, the pharmaceutical company and the effects of advertising. Section 3 derives our results. Section 4 highlights areas that empirical research might fruitfully pursue to empirically estimate particular effects of DTCA.

\section{The Model}

Our model considers a single health condition for which there are two alternative treatments. One treatment is supplied by a profit maximizing pharmaceutical drug company that advertises directly to consumers. The other treatment is not advertised. There is a population of heterogeneous individuals. To be diagnosed and treated an individual must consult with a physician. Advertising has two potential effects, it informs consumers and it persuades them. We describe below our assumptions about individuals, the pharmaceutical company, and doctors. 


\section{$2.1 \quad$ Individuals}

Our economy consists of a continuum of heterogeneous individuals. A fraction $q \in(0,1)$ of the population has a health condition (health status $I=$ sick), and the rest $1-q$ of the population is healthy (health status $I=$ healthy). Individuals differ in how much information they have (on the condition and the available treatments), and also in how they respond to treatments.

Each individual obtains a signal $S$ which can take a value $h$ or $s$. The signal $s$ can be symptoms or observed risk factors that influence people's beliefs about whether they might need a treatment. We assume that a sick person always obtains the signal $s$ (has symptoms), and a healthy person has a probability $\sigma \in\left(\frac{1}{2}, 1\right]$ of obtaining the signal $h$ (no symptoms). ${ }^{2}$ Thus,

$$
\begin{aligned}
& \operatorname{prob}(S=s \mid I=\operatorname{sick})=1 \text { and } \operatorname{prob}(S=h \mid I=\text { sick })=0 . \\
& \operatorname{prob}(S=s \mid I=\text { healthy })=1-\sigma \text { and } \operatorname{prob}(S=h \mid I=\text { healthy })=\sigma
\end{aligned}
$$

The signal is more informative the higher $\sigma$. If $\sigma=1$, a health person never experiences the associated symptoms.

An individual who visits the doctor can receive no treatment, or one of two available treatments: treatment $\in\{0,1,2\}$. Treatment 1 is a prescription drug. This treatment

\footnotetext{
${ }^{2}$ Our results remain qualitatively the same if we generalize this assumption so that there is a probability $1 \geq \sigma_{s}>\frac{1}{2}$ that a sick person obtains the signal $s$.
} 
is supplied by a profit maximizing pharmaceutical company that may choose to advertise the drug directly to consumers. The alternative treatment 2 is not advertised. It can be a therapeutic life style change or another competitively supplied treatment for the same condition.

Individuals are heterogeneous in their benefits from treatments. For example, individuals may be expected to respond differently to the treatments depending on health determinants such as age, gender, being a smoker, use of other drugs, preferences related to life style changes, health measures such as level of cholesterol and so on. For simplicity we assume these factors can be summarized with a single index $x \in[0,1]$, which we refer to as the patient's type. We denote the benefit (net of all side effects and risks associated with the treatment) over the no treatment option for a sick individual who has type $x$ by $b_{t}(x)$ for $t \in\{1,2\}$. The higher $x$ the more beneficial treatment 2 is, and the less beneficial treatment 1 is:

$$
\frac{d b_{1}(x)}{d x}<0 \text { and } \frac{d b_{2}(x)}{d x}>0 .
$$

Facing a price $p_{t}$ a sick individual's benefit from treatment $t$ net of its price is given by $\left(b_{t}(x)-p_{t}\right)$. All sick individuals are better off with their most preferred treatment than without any. An individual with type $x=0$ is better off when prescribed treatment 1 , and an individual with type $x=1$ is better off when prescribed treatment 2 .

$$
b_{2}(0)-p_{2}>b_{1}(0)-p_{1} \text { and } b_{2}(1)-p_{2}<b_{1}(1)-p_{1}
$$


An individual draws her type $x$ independently from a distribution with a cumulative distribution function $F(x)$, and a density $f(x)$. Healthy individuals are assumed to have a negative net benefit from treatment.

A fraction $\lambda$ of individuals are informed, they are aware of the existence of the health condition, the implications of the signal and the availability of treatments. A fraction $1-\lambda$ are uniformed.

An uninformed individual who has the symptoms visits the doctor if her benefit from going to a doctor, denoted by $U_{s}$, exceeds the cost. A condition that is associated with more severe symptoms has a higher $U_{s}$ and the individual would be more likely seek a doctor's advice. Note that severe symptoms are not necessarily more accurate. High fever or strong pain, for example, may be severe symptoms and are likely to induce even an uninformed individual to visit the doctor, but these symptoms may be weak signals for a specific condition (say the flu). On the other hand, a risk factor which is a good predictor of the health condition might not be "severe" in the sense that the person might not experience any major discomfort and would not likely visit the doctor if uninformed.

An informed individual observes her signal, she updates the probability of being sick. We use the distribution of signals defined in (1) and in (2), and Bayes rule, to derive the 
probability that a person is sick given her signal:

$$
\begin{aligned}
& q_{s}=\operatorname{prob}(I=\operatorname{sick} \mid S=s)=\frac{\operatorname{prob}(I=\operatorname{sick} \cap S=s)}{\operatorname{prob}(S=s)}=\frac{q}{q+(1-q)(1-\sigma)} \\
& q_{h}=\operatorname{prob}(I=\operatorname{sick} \mid S=h)=\frac{\operatorname{prob}(I=\operatorname{sick} \cap S=h)}{\operatorname{prob}(S=h)}=0 .
\end{aligned}
$$

An individual who visits a doctor must pay direct and indirect costs. If the person is uninsured, she pays the fee doctor charges for an office visit. If she is insured, she pays the amount of the co-payment. An individual also pays indirectly if the visiting the doctor causes disutility or because she has a high opportunity cost of the time she must spend. Each person's total cost of a doctor visit is independently drawn from a distribution with density $g(\varepsilon)$ and a cumulative distribution function $G(\varepsilon)$ on $[0, \bar{\varepsilon}]$. To be diagnosed and treated a consumer must first visit a physician. Consumers weigh the cost of a visit against the perceived benefit they expect to receive if they are treated.

\subsection{Pharmaceutical company and DTCA}

To model the informative nature of advertising, we assume a share $\lambda$ of individuals are informed. These individuals are aware of the condition and its possible treatments. Advertising increases the share of informed consumers, $\lambda=\lambda(A)$ where $\lambda(0) \geq 0, \lambda^{\prime}(A)>0$ with $\lim _{A \rightarrow \infty} \lambda^{\prime}(A)=0$, at a decreasing rate, $\lambda^{\prime \prime}(A) \leq 0$.

To model the persuasive nature of advertising, we assume advertising increases the

perceived benefit from the advertised drug $\frac{\partial b_{1}(x, A)}{\partial A}>0$, at a decreasing rate $\frac{\partial b_{1}^{2}(x, A)}{\partial A^{2}}$. This 
effect vanishes as advertising becomes very high $\lim _{A \rightarrow \infty} \frac{\partial b_{1}(x, A)}{\partial A}=0$. We assume for simplicity that all informed individuals are exposed to advertising.

\subsection{Physicians}

When physicians treat patients they learn whether patients are insured, they diagnose each person's condition, and they determine the best treatment for a patient of a given type $x$. Physicians act as agents on behalf of their patients. Although we assume all physicians are equally qualified, there are two types of physicians that differ in their prescribing behavior.

Physicians of the first type, "unpersuaded physicians", prescribe the drug independently of the patient's exposure to advertising. That is, these physicians prescribe the treatment that yields the highest pre-DTCA net benefit. They choose a treatment independently of whether and how much the firm has advertised that treatment. Physicians of this type follow a decision rule given by:

$$
\text { treatment }=\left\{\begin{array}{ccc}
\text { no treatment } & \text { if } & I=\text { healthy } \\
\text { advertised drug } & \text { if } & I=\text { sick, } x \leq x_{0} \\
\text { alternative treatment } & \text { if } \quad I=\text { sick, } x>x_{0}
\end{array}\right.
$$

where $x_{0}$ solves

$$
b_{1}\left(x_{0}\right)-p_{1}=b_{2}\left(x_{0}\right)-p_{2}
$$

The second type of physician, "persuaded physicians", prescribes according to con- 
sumers' perceived benefits, which are potentially affected by DTCA. They prescribe the treatment that yields the highest perceived post-DTCA benefit. Their choice of treatment is given by:

$$
\text { treatment }\left\{\begin{array}{ccc}
\text { no treatment } & \text { if } \quad I=\text { healthy } \\
\text { advertised drug } & \text { if } \quad I=\text { sick, } x \leq \widetilde{x_{0}} \\
\text { alternative treatment } & \text { if } \quad I=\text { sick, } x>\widetilde{x_{0}}
\end{array}\right.
$$

where $\widetilde{x_{0}}$ solves

$$
b_{1}\left(\widetilde{x_{0}}, A\right)-p_{1}=b_{2}\left(\widetilde{x_{0}}\right)-p_{2} .
$$

When there is no DTCA $(A=0)$ both types of doctors prescribe the same treatment $\left(x_{0}=\widetilde{x_{0}}\right)$ because perceived and actual benefits are the same. As advertising level increases, $\widetilde{x_{0}}$ increases, and more patients are prescribed treatment 1 . Individuals draw a doctor type at random, a persuaded physicians with probability $\mu$, and an unpersuaded physicians with a probability $1-\mu$.

\subsection{Timing}

At first, nature draws all random variables for each individual: health condition $I$ (sick or health), type $x$ (determining benefit from treatment), signal $S$ (symptoms of being ill), doctor type (persuaded physicians or unpersuaded), and the cost of a doctor visit $\varepsilon$. The pharmaceutical company decides how much to spend on DTCA. Some individuals are 
exposed to DTCA and become informed. All individuals observe their signal and cost of a doctor visit. Based on her signal, the cost of doctor visit and her information, an individual decides whether or not to visit a doctor. Doctors diagnose the condition and prescribe a treatment.

\section{Analysis}

\subsection{Individual decisions to visit the doctor}

An individual chooses to visit a doctor if, given the information she has, she expects the benefit to exceed the cost. Using (4) and (6), which describe the treatment choice of each doctor type, we can express what benefit each person perceives she will get if she visits a doctor. An informed sick person perceives an expected net benefit of:

$$
B(A)=\left[\begin{array}{c}
(1-\mu) \underbrace{\left(\int_{0}^{x_{0}}\left[b_{1}(x, A)-p_{1}\right] f(x) d x+\int_{x_{0}}^{1}\left[b_{2}(x)-p_{2}\right] f(x) d x\right)}_{\text {if unpersuaded doctor }} \\
+\mu \underbrace{\left(\int_{0}^{x_{0}}\left[b_{1}(x, A)-p_{1}\right] f(x) d x+\int_{\widetilde{x_{0}}}^{1}\left[b_{2}(x)-p_{2}\right] f(x) d x\right)}_{\text {if persuaded doctor }}
\end{array}\right]
$$

An individual who observes a signal $S$ and who sees DTCA level $A$ perceives the expected benefit from a doctor visit as:

$$
V_{s}(A)=q_{s} B(A) \text { and } V_{h}(A)=0 .
$$


where, $q_{s}$ is given by (3).

An individual whose signal is $h$ will not visit the doctor. An individual who has a signal $s$ and draws a disutility $\varepsilon$ from doctor visits will visit the doctor if she is informed and

$$
V_{s}(A) \geq \varepsilon
$$

or if she is uninformed and

$$
U_{s} \geq \varepsilon
$$

We assume $V_{s}(0) \geq U_{s}$ so that for any advertising level informed consumers are at least as likely to visit a doctor as uninformed consumers.

In our first lemma we state how (given a signal $s$ ) the expected benefit from a doctor visit depends on the level of advertising, and on the characteristics of the health condition. These relationships will prove useful later.

Lemma 1 An informed individual's perceived benefit from going to the doctor when she has symptoms, $V_{s}(A)$, increases with advertising $A$. For any level of DTCA $A>0$, this perceived benefit increases with $q$ (the prevalence of the condition), with $\mu$ (share of doctors who prescribe according to consumers" preferences) and with $\sigma$ (the accuracy of the signal). The marginal effect of advertising $V_{s}^{\prime}(A)$ also increases with $q, \mu$ and $\sigma$.

All proofs are provided in the appendix. 


\subsection{Volume of doctor visits}

Individuals with a signal $h$ do not visit the doctor. The probability that an individual with a signal $s$ visits the doctor is $G\left(U_{s}\right)$ if she is uninformed and $G\left[V_{s}(A)\right]$ if she is informed. The expected volume of doctor visits is therefore given by:

$$
D_{d o c}(A)=\operatorname{prob}(S=s)\left\{\lambda(A) G\left[V_{s}(A)\right]+(1-\lambda(A)) G\left(U_{s}\right)\right\} .
$$

Proposition 1 The volume of office visits $D_{\text {doc }}(A)$ increases with the level of DTCA A.

There are two reasons for the positive effect of advertising on doctor visits: DTCA increases the share of informed individuals (which has an overall positive effect since informed individuals are more likely to visit a doctor) and it increases the propensity of informed individuals to visit the doctor.

\subsection{Effect of DTCA on Demand for Treatment}

We have assumed consumers need a doctor to prescribe their treatment and that doctors only prescribe to sick individuals. Therefore, demand for either treatment depends on the volume of sick people who see a doctor. Uninformed individuals do not ask for a specific treatment, they get prescribed according to the threshold $x_{0}$. Informed individuals ask the doctor about the advertised treatment, if they are seen by a persuaded doctor, they are prescribed according to the higher persuaded threshold $\widetilde{x_{0}}$. 
Treatment 1 is prescribed to individuals who have the condition, who went to see a doctor and whose type $x$ is such that their doctor chooses treatment 1 over treatment 2 . Therefore, consumers demand the advertised drug (treatment 1) according to:

$$
D_{1}(A)=\lambda(A) q G\left[V_{s}(A)\right]\left\{F\left(x_{0}\right)+\mu\left[F\left(\widetilde{x_{0}}\right)-F\left(x_{0}\right)\right]\right\}+(1-\lambda(A)) q G\left(U_{s}\right) F\left(x_{0}\right)
$$

Proposition 2 Demand for drug 1 (the advertised treatment) increases with DTCA.

The increase in demand results from two effects: direct to consumer advertising increases the fraction of informed consumers who are more likely to seek medical advice, and it increases the share of consumers who go to the doctor and are prescribed the drug due to the persuasive effect of advertising.

Consumers demand for the alternative treatment is:

$D_{2}(A)=\lambda(A) q G\left[V_{s}(A)\right]\left[1-F\left(x_{0}\right)-\mu\left(F\left(\widetilde{x_{0}}\right)-F\left(x_{0}\right)\right)\right]+(1-\lambda(A)) q G\left(U_{s}\right)\left[1-F\left(x_{0}\right)\right]$.

DTCA of treatment 1 affects the volume of treatment 2 prescriptions in two opposing ways: (i) a positive market expansion effect - DTCA induces more people to visit a doctor, some of whom will be prescribed treatment 2 ; (ii) a negative business stealing - DTCA persuades some consumers who would otherwise get treatment 2 to ask their doctors for treatment 1 . If $\mu$ (the share of persuaded doctors) is small then this "business stealing" effect is small and the market expansion effect dominates. In this case, DTCA increases 
the demand for treatment 2 - some consumers who would have gone untreated without DTCA now get treatment.

Proposition 3 DTCA of treatment 1 has an ambiguous effect on the demand for treatment

2. If $\mu$ (the share of persuaded doctors) is small enough then demand for treatment 2 increases with DTCA of treatment 1.

\subsection{Choice of DTCA}

A pharmaceutical company supplies treatment 1 . The cost of the treatment is $c_{1}$. In the pharmaceutical industry there is generally prices are often negotiated with large buyers (see Berndt, 2002). Insurance coverage and drug prices may be set in long term contracts. Insured consumers might pay a constant price (uniformly set for many drugs). The price the pharmaceutical company receives for the drug does not generally equal the price consumers pay. In light of these issues, we adopt the simplifying assumption that the price of the drug and insurance contracts are determined before the firm chooses its advertising level. We focus on the choice of advertising expenditure $A$ given the price the firm negotiated and the prices consumers face. Let the price of the drug received by the firm be $P$, and denote demand as a function of this price and advertising by $D_{1}(P, A)$. In the next subsection we consider the effects of advertising on drug price.

Profits for a given level of advertising are given by

$$
\pi(A)=\left(P-c_{1}\right) \times D_{1}(P, A)-A
$$


The pharmaceutical firm that supplies treatment 1 drug maximizes profits with an optimal choice of DTCA expenditure $A$.

$$
\max _{A \geq 0}\left[\left(P-c_{1}\right) \times D_{1}(P, A)-A\right]
$$

Assume $\left(P-c_{1}\right) \times D_{1}^{\prime}(P, 0)>1$ so that profit is increasing at $A=0 ;^{3}$ given our previous assumptions, $D_{1}^{\prime}(P, A) \rightarrow 0$ when $A \rightarrow \infty$ so that profit is decreasing for $A \rightarrow \infty$. Hence, the level of advertising that maximizes profit is interior and must satisfy the first order condition,

$$
F O C=\left(P-c_{1}\right) \times \frac{\partial D_{1}(P, A)}{\partial A}-1=0
$$

Comparative statics with respect to any parameter $\xi \in\left\{\mu, q, \sigma, U_{s}\right\}$ keeping the other parameters constant can be found by implicit differentiation:

$$
\underbrace{\frac{\partial F O C(A, \xi)}{\partial A}}_{-} \frac{d A}{d \xi}+\frac{\partial F O C(A, \xi)}{\partial \xi}=0 .
$$

From the second order condition of profit maximization, $\frac{\partial F O C(A)}{\partial A}<0$. Therefore,

$$
\operatorname{sign}\left(\frac{d A}{d \xi}\right)=\operatorname{sign}\left(\frac{\partial F O C(P, A, \xi)}{\partial \xi}\right)=\operatorname{sign}\left(\frac{\partial D_{1}^{2}(P, A, \xi)}{\partial \xi \partial A}\right)
$$

Proposition 4 The profit maximizing level of advertising $A^{*}$ decreases with $U_{s}$ (the propen-

\footnotetext{
${ }^{3}$ This will hold true when, as $A$ gets close to 0 , advertising has a sufficiently large marginal effect on the number of informed consumers, and or on their perceived benefit from advertising.
} 
sity of uninformed to visit the doctor). Assume the density of doctor visit costs is nondecreasing, $g^{\prime}(e) \geq 0$ (e.g., for a uniform distribution), then the profit maximizing level of advertising $A^{*}$ increases with $\mu$ (proportion of doctors who serve persuaded consumers), $q$ (prevalence of the disease), and $\sigma$ (the probability that a healthy person does not have the symptoms).

We describe below the intuition for these findings. As we discussed earlier, DTCA increases profits in two ways: by expanding the market - increasing the number of individuals seeking medical care; and by business stealing - attracting more individuals to the advertised treatment instead of the alternative treatment. Because only doctors who accede to the wishes of persuaded consumers alter their prescribing behavior in favor of the advertised drug, advertising is more effective if there are more doctors of this type (if $\mu$ is high). Therefore, we find higher investment in advertising when there are more persuaded doctors. Observe that the presence of internet prescription services might be an example of an increase in $\mu$. The share of persuaded doctors can also be linked to detailing efforts (advertising to doctors).

Advertising increases with the prevalence of the condition. This result occurs because the potential market is larger and the expected benefit of each informed individual from going to the doctor is higher the more likely she would need treatment. Advertising level is higher the higher is $\sigma$, which measures the accuracy the signal. That is, when a healthy person is less likely to have the symptoms associated with the conditions, profit maximizing 
spending on DTCA is higher. ${ }^{4}$ The parameter $U_{s}$ captures how likely uninformed individuals are to visit a doctor when they have a signal $s . U_{s}$ will be higher when symptoms are more severe. DTCA decreases with $U_{s}$ because if individuals visit the doctor even when they are uninformed there is less incentive to inform them.

Our findings suggest that empirical research would benefit from carefully characterizing symptoms of different diseases or conditions because observed DTCA spending is likely to systematically vary with the nature of the symptoms.

\subsection{Price}

We have shown that for any given price, the demand for the advertised drug increases with DTCA. This could strengthen the firm's bargaining position in price negotiations, which could result in a higher price. Formally modeling price negotiations between a pharmaceutical company and large buyers is beyond the scope of our paper. Instead, in this section, we illustrate the possible effects of advertising on drug price in a simple monopoly pricing model. The firm solves:

$$
\max _{P \geq 0}\left[\left(P-c_{1}\right) \times D_{1}(P, A(P))-A(P)\right],
$$

\footnotetext{
${ }^{4}$ In complementary analysis we generalize the model to allow for a probability $\sigma_{s} \leq 1$ that a sick person has the symptoms. Advertising increases with $\sigma_{s}$ if the propensity of uninformed individuals to visit the doctor $U_{s}$ is small enough. For large values of $U_{s}, A^{*}\left(\sigma_{s}\right)$ is $U$-shaped. Large values of $U_{s}$, corresponds to severe symptoms that cause even uninformed consumers to visit the doctor. In this case, more informative signals will cause advertising to fall.
} 
where $A(P)$ denotes the optimal advertising expenditure for a price $P$. The first order condition for profit maximization is

$$
D_{1}(P, A(P))+\left(P-c_{1}\right) \times \frac{\partial D_{1}(P, A(P))}{\partial P}+\underbrace{\left[\left(P-c_{1}\right) \times \frac{\partial D_{1}(P, A(P))}{\partial A}-1\right]}_{=0} \frac{d A(P)}{d P}=0 .
$$

The last term vanishes when advertising is chosen optimally. This first order can be rearranged to imply the standard inverse elasticity rule:

$$
\frac{1}{|\varepsilon|}=\frac{1}{-\frac{\partial D_{1}(P, A)}{\partial P} \frac{P}{D_{1}(P, A)}}=\frac{\left(P-c_{1}\right)}{P}
$$

If the elasticity of demand is lower when the pharmaceutical firm engages in DTCA then the firm will choose a higher price than without DTCA. The persuasive nature of advertising, as well as the increase in quantity demanded for every given price both contribute to higher demand elasticity. ${ }^{5}$ Indeed, some evidence suggests that DTCA may raise the price a firm can charge for the advertised drug. In an empirical investigation, Dave and Saffer (2012) find that DTCA contributes to a growth in drug expenditures, and that two-thirds of this impact is driven by higher demand and the remainder due to higher prices.

\footnotetext{
${ }^{5}$ In the model, the effect of advertising on demand elasticity can depend on the distribution functions $F$ and $G$, and on the functional forms of $\lambda(A)$ and $b_{t}(x, A)$. For uniform distributions, linear benefit functions and a fixed number of informed consumers it can be shown that demand elasticity is higher with advertising than without advertising.
} 


\subsection{Social Welfare}

In this section we discuss the effects of direct to consumer advertising on social welfare.

We argue that, from a social perspective, the privately chosen level of DTCA can either be excessive or insufficient. Whether DTCA is excessive will depend on the nature of advertising (informative or persuasive), the prevalence of persuaded doctors and on whether consumers are insured. Let social welfare be the sum of the profit of the company selling treatment 1 drug (profit from the other treatment is zero) and the social consumer surplus. Social consumer surplus accounts for the actual (not persuaded) benefits and true social cost of the drug and of doctor visits.

$$
W(A)=\Pi(A)+C S(A) .
$$

If $W^{\prime}\left(A^{*}\right)<0$ then social benefit will (locally) increase if DTCA falls. In this case we say that the private level is excessive or too high. If $W^{\prime}\left(A^{*}\right)>0$ social benefit will (locally) increase if DTCA rises. In this case we say private spending is insufficient or too low. The private level of advertising $A^{*}$ is such that $\Pi^{\prime}\left(A^{*}\right)=0$. Evaluating $W^{\prime}(A)$ at the private level of advertising $A^{*}$ we have $W^{\prime}\left(A^{*}\right)=C S^{\prime}\left(A^{*}\right){ }^{6}$ We argue that the sign of $W^{\prime}\left(A^{*}\right)$ is ambiguous.

Suppose, that drug advertising is persuasive (increases perceived benefits) but not in-

\footnotetext{
${ }^{6}$ We ignore any disutility a consumer might experience when she sees DTCA. We assume that, if such disutility were severe enough, firms would refuse to air those advertisements. Consequently, seeing more DTCA does not reduce the consumers' time viewing favorite shows.
} 
formative (does not change the share of informed consumers), and that the population is insured. Consumers who go to the doctor overestimate the benefit of doing so (due to the persuasive nature of advertising) and underestimate the cost of the visit (because of insurance). As advertising increases, more consumers go to the doctor. For the marginal consumers, persuaded benefits equal the costs of the doctor visit and the drug, but social benefits are lower than private benefits and social costs higher than private costs, therefore, social consumer surplus declines, $C S^{\prime}\left(A^{*}\right)<0$. Hence, $W^{\prime}\left(A^{*}\right)<0$, the private level of advertising is excessive. Under this scenario, if the Affordable Care Act successfully insures every US citizen it will be more likely that private spending on DTCA would be excessive, especially if advertised drugs treat well-known conditions and the DTCA does not convey much information (for example, because the treatments have been in the market for a while and the role of information is small). When comparing the potential social welfare gains and losses in countries considering whether or not to allow DTCA, our model suggests that all else equal, the potential welfare gains are lower in countries that have universal health insurance coverage.

If the share of insured consumers is high and the difference between the price paid by consumer for the drug and the price paid to the drug company is high, then even informative advertising can be excessive. A policy change that significantly increases the share of insured individuals in the population could thus change the level of private advertising from being insufficient to being excessive even if advertising is only informative. The difference between the seller and the buyer price can however be lower in countries that 
aggressively negotiate drug prices, mitigating the associated distortion in advertising levels.

When consumers are uninsured and the firm has market power, consumers pay a price that exceeds the marginal cost of the drug. In this case, absent DTCA there is underprovision of treatment. DTCA can increase welfare by increasing doctor visits and treatment. Informative and even persuasive advertising can increase efficiency as it increases demand for doctor visits and treatments.

An additional source of social cost of DTCA might be the increase in drug prices. Note however that if the majority of the population is insured this may not be a significant cost, because in this case higher prices would not result in underproduction of the drug.

\section{Concluding remarks}

We summarize our findings and suggest some limitations of the model and directions for future work. This paper modeled DTCA as informative and persuasive. Exposure to DTCA brings more people to see doctors and to get treatment through two possible channels:

(i) more individuals become aware of the condition and the availability of treatment;

(ii) advertisements persuade consumers that the benefits of the drug are higher than they actually are.

The persuasive aspect of advertising is mitigated by the fact that prescription drugs have doctors as gatekeepers. DTCA will increase the demand for the advertised drug. Its effect on the demand for an alternative treatment is ambiguous - demand for the 
alternative treatment may increase due to the information effect, and even due to persuasion as long as a large share of the doctors continue prescribing the most appropriate treatment, which, in some cases, is the alternative treatment. If a large share of doctors prescribe according to consumers' persuaded benefits, then a decline in the demand for the alternative treatment may arise due to a change in treatment choice from the alternative treatment to the advertised drug. Such distortion in treatment choice can generate welfare losses.

DTCA will be more profitable when a large share of potential consumers are unaware of the condition and its treatment, and also when the prevalence of the condition in the population is high. For conditions associated with more informative symptoms, more individuals who have symptoms will seek doctor's advice. The profitability of advertising also depends on the share of the population that is insured. When more individuals are insured a larger share will respond to advertising by going to the doctor and getting treatment, making advertising more profitable. Advertising is also more profitable the larger the share of doctors who prescribe a drug requested by their persuaded consumers. In our model we have taken the share of persuaded doctors as exogenously given. This share, however, might be higher with large detailing efforts. Our finding that DTCA increases with the share of persuaded doctor is consistent with Brekke and Kuhns (2006) findings that detailing and DTCA are complementary. Policies aimed at monitoring doctors' prescribing behavior or providing guidance for when to favor the alternative treatment over the advertised one can help keep the share or persuaded doctors lower, and avoid the prescribing distortion associated with persuasive DTCA. We noted that, absent careful regulatory attention, the 
presence of internet prescription drug dispensaries may lead to welfare losses.

Health insurance can create a gap between the price consumers pay and the price the seller obtains. Similar gaps exist for the cost of doctor visits. When a large share of consumers have health insurance that covers some of their drug and doctor visit expenses, DTCA is more likely to be too high from a social perspective. In such situation, even informative advertising can create welfare losses. However, when consumers are largely uninsured, drug prices that exceed the marginal cost of production can result in under provision of the drug. Increased demand, even if it resulted from an increase in perceived benefits, might efficiently increase use of the drug.

A positive effect of DTCA that was not accounted for here is the potential positive effect on drug R\&D investments. If DTCA increases anticipated profits for the pharmaceutical company then it could potentially induce more $R \& D$ investment. We also ignored the possibility that DTCA helps consumers adopt or maintain new healthier behavior. It might do so because it reminds them frequently of the benefits of the healthy behavior. Some evidence supports this idea. For example, Avery et al. (2007) show that DTCA advertising of pharmaceutical smoking cessation products induces smokers to attempt to quit and to successfully quit, even when they do not use a smoking cessation product to do so.

Despite these omissions, our model provides a formal framework that researchers can use to guide empirical investigations of various aspects of the market for prescription drugs when firms may advertise those drugs directly to consumers. The predictions of the model, 
especially those that are ambiguous, need to be empirically tested. That work remains for future research. 


\section{Appendix}

Proof of Lemma 1. By definition of $V_{s}(A)$ we have

$$
V_{s}^{\prime}(A)=q_{s} B^{\prime}(A)=q_{s}\left[\begin{array}{c}
(1-\mu) \int_{0}^{x_{0}} \frac{\partial b_{1}(x, A)}{\partial A} f(x) d x+\mu \int_{0}^{\widetilde{x_{0}}} \frac{\partial b_{1}(x, A)}{\partial A} f(x) d x \\
+\mu \underbrace{\left\{\left[b_{1}\left(\widetilde{x_{0}}, A\right)-p_{1}\right]-\left[b_{2}\left(\widetilde{x_{0}}\right)-p_{2}\right]\right\}}_{=0} f\left(\widetilde{x_{0}}\right) \frac{d \widetilde{x_{0}}}{d A}
\end{array}\right]>0 .
$$

Because perceived benefits increase with advertising, and at $\widetilde{x_{0}}$ a consumer is indifferent between the two drugs, $V_{s}^{\prime}(A)>0$.

We derive the effects of parameters on $V_{s}(A)$ for a given $A$. Note that $q_{s}$ is a function of the parameters $q, \sigma$ as given in $(3)$, but $B(A)$ does not depend on these parameters. We differentiate each of the functions of interest with respect to each parameter

$$
\begin{aligned}
\frac{d}{d q} V_{s}(A) & =\frac{(1-\sigma)}{(q+(1-q)(1-\sigma))^{2}} B(A)>0 . \\
\frac{d}{d \sigma} V_{s}(A) & =\frac{q(1-q)}{(q+(1-q)(1-\sigma))^{2}} B(A)>0 . \\
\frac{d}{d \mu} V_{s}(A) & =q_{s} \frac{d B(A)}{d \mu}=q_{s}\left[\left(\int_{x_{0}}^{x_{0}}\left\{\left[b_{1}(x, A)-p_{1}\right]-\left[b_{2}(x)-p_{2}\right]\right\} f(x) d x\right)\right]>0 .
\end{aligned}
$$

Since in the range $\left(x_{0}, \widetilde{x_{0}}\right)$ the person's perceived benefit from treatment 1 is higher than the benefit from treatment 2 . 
Finally, we derive the effects of these parameters on $V_{s}^{\prime}(A)$ :

$$
\begin{aligned}
\frac{d}{d q} V_{s}^{\prime}(A) & =\frac{(1-\sigma)}{(q+(1-q)(1-\sigma))^{2}} B^{\prime}(A)>0 . \\
\frac{d}{d \sigma} V_{s}^{\prime}(A) & =\frac{q(1-q)}{(q+(1-q)(1-\sigma))^{2}} B^{\prime}(A)>0 . \\
\frac{d}{d \mu} V_{s}^{\prime}(A) & =q_{s} \frac{d B^{\prime}(A)}{d \mu}=q_{s}\left[\int_{x_{0}}^{\widetilde{x_{0}}} \frac{\partial b_{1}(x, A)}{\partial A} f(x) d x\right]>0 .
\end{aligned}
$$

Proof of Proposition 1. We rearrange $D_{d o c}(A)$ in (11) to obtain

$$
D_{d o c}(A)=\operatorname{prob}(S=s)\left\{\lambda(A)\left[G\left(V_{s}(A)\right)-G\left(U_{s}\right)\right]+G\left(U_{s}\right)\right\} .
$$

Differentiating with respect to $A$,

$$
\frac{d}{d A} D_{d o c}(A)=\operatorname{prob}(S=s)\left\{\lambda(A) g\left(V_{s}(A)\right) \frac{d V_{s}(A)}{d A}+\lambda^{\prime}(A)\left[G\left(V_{s}(A)\right)-G\left(U_{s}\right)\right]\right\} .
$$

Since $\left[G\left(V_{s}(A)\right)-G\left(U_{s}\right)\right]>0, \lambda^{\prime}(A)>0$ and $\frac{d V_{s}(A)}{d A}>0$ we have $\frac{d}{d A} D_{d o c}(A)>0$.

Proof of Proposition 2. We rearrange equation (12) which defines the demand to obtain:

$D_{1}(A)=q \lambda(A)\left(G\left[V_{s}(A)\right]-G\left(U_{s}\right)\right) F\left(x_{0}\right)+q \mu \lambda(A) G\left[V_{s}(A)\right]\left[F\left(\widetilde{x_{0}}\right)-F\left(x_{0}\right)\right]+q G\left(U_{s}\right) F\left(x_{0}\right)$. 
We differentiate $D_{1}(A)$ with respect to $A$ :

$$
\begin{aligned}
\frac{d D_{1}(A)}{d A}= & q\left\{\lambda(A) g\left(V_{s}(A)\right) \frac{d V_{s}(A)}{d A}+\lambda^{\prime}(A)\left[G\left(V_{s}(A)\right)-G\left(U_{s}\right)\right]\right\} F\left(x_{0}\right) \\
& +q \mu\left\{\lambda(A) g\left[V_{s}(A)\right] \frac{d V_{s}(A)}{d A}+\lambda^{\prime}(A) G\left[V_{s}(A)\right]\right\}\left[F\left(\widetilde{x_{0}}\right)-F\left(x_{0}\right)\right] \\
& +q \mu \lambda(A) G\left[V_{s}(A)\right] f\left(\widetilde{x_{0}}\right) \frac{d \widetilde{x_{0}}}{d A} .
\end{aligned}
$$

Implicitly differentiating $\widetilde{x_{0}}$ as defined in (7):

$$
\frac{d \widetilde{x_{0}}}{d A}=\frac{\partial b_{1}\left(\widetilde{x_{0}}, A\right)}{\partial A}\left(\frac{d b_{2}\left(\widetilde{x_{0}}\right)}{d x}-\frac{b_{1}\left(\widetilde{x_{0}}, A\right)}{\partial x}\right)>0
$$

We also know that $\lambda^{\prime}(A)>0, V_{s}(A)>U_{s}$, and $\frac{d V_{s}(A)}{d A}>0$. All the terms in the derivative of $D_{1}(A)$ are positive and hence, demand for treatment 1 is increasing in $A$.

Proof of Proposition 3. Rearrange $D_{2}$ as given in (13).

$$
D_{2}(A)=q \lambda(A)\left(G\left[V_{s}(A)\right]-G\left(U_{s}\right)\right)\left[1-F\left(x_{0}\right)\right]-q \mu \lambda(A) G\left[V_{s}(A)\right]\left(F\left(\widetilde{x_{0}}\right)-F\left(x_{0}\right)\right)+q G\left(U_{s}\right)\left[1-F\left(x_{0}\right)\right] .
$$

Differentiating the demand we find,

$$
\begin{aligned}
\frac{d D_{2}(A)}{d A}= & q\left\{\lambda(A) g\left(V_{s}(A)\right) \frac{d V_{s}(A)}{d A}+\lambda^{\prime}(A)\left[G\left(V_{s}(A)\right)-G\left(U_{s}\right)\right]\right\}\left[1-F\left(x_{0}\right)\right] \\
& -q \mu \lambda^{\prime}(A) G\left[V_{s}(A)\right]\left[F\left(\widetilde{x_{0}}\right)-F\left(x_{0}\right)\right]-q \mu \lambda(A) g\left[V_{s}(A)\right] \frac{d V_{s}(A)}{d A}\left[F\left(\widetilde{x_{0}}\right)-F\left(x_{0}\right)\right] \\
& -q \mu \lambda(A) G\left[V_{s}(A)\right] f\left(\widetilde{x_{0}}\right) \frac{d \widetilde{x_{0}}}{d A}
\end{aligned}
$$


The terms in the first line are all positive and capture the informative effects of advertising. The terms in the second and third line are negative for $\mu>0$ and capture the business stealing effects of advertising. The overall effect is ambiguous. For $\mu=0$, there is no business stealing effect and demand for treatment 2 increases with advertising. When advertising is not informative,

Proof of proposition 4. We argued that for any parameter $\xi$, sign $\left(\frac{d A}{d \xi}\right)=\operatorname{sign}\left(\frac{\partial D_{1}^{2}(A)}{\partial \xi \partial A}\right)$. Recall that by lemma $1, V_{s}(A)$ and $V_{s}^{\prime}(A)$ increase with $q, \sigma$, and $\mu$, but do not depend on $U_{s}$. We consider the effect of each parameter on $\frac{\partial D_{1}(A)}{\partial A}$ as given in (15):

Using the results of lemma 1 we observe that if $g^{\prime}(V) \geq 0$ (e.g. uniform distribution) then all the terms in (15) are increasing with $\mu, \sigma$ and $q$ and hence,

$$
\begin{aligned}
& \operatorname{sign}\left(\frac{d A^{*}}{d \mu}\right)=\frac{\partial D_{1}^{2}(A)}{\partial \mu \partial A}>0 . \\
& \operatorname{sign}\left(\frac{d A^{*}}{d q}\right)=\frac{\partial D_{1}^{2}(A)}{\partial q \partial A}>0 . \\
& \operatorname{sign}\left(\frac{d A^{*}}{d \sigma}\right)=\frac{\partial D_{1}^{2}(A)}{\partial \sigma \partial A}>0 .
\end{aligned}
$$

The effect of $U_{s}$ :

$$
\operatorname{sign}\left(\frac{d A^{*}}{d U_{s}}\right)=\operatorname{sign}\left(\frac{\partial D_{1}^{2}(A)}{\partial U_{s} \partial A}\right)=-q \lambda^{\prime}(A) g\left(U_{s}\right) F\left(x_{0}\right)<0
$$




\section{References}

Aikin K, Swasy J, and Braman A. 2004. "Patient and Physician Attitudes and Behaviors Associated With DTC Promotion of Prescription Drugs," Summary FDA Survey Research Results, http://www.fda.gov/downloads/AboutFDA/CentersOffices/CDER/ucm109875.pdf

Avery, Rosemary, Kenkel, Donald, Lillard, Dean, and Mathios, Alan. 2007. "Private Profits and Public Health: Does DTC Advertising of Smoking Cessation Products Encourage Smokers to Quit?" Journal of Political Economy. Vol. 115 (3): 447-481 (also NBER working paper 11938).

Brekke, K. R., Kuhn, M. "Direct to Consumer Advertising in Pharmaceutical Markets." Journal of Health Economics, Vol. 25 (2006), pp. 102-130.

Bradford, D., Kleit, A. 2011. "Can Credence Advertising Effects Be Isolated? Can They Be Negative?: Evidence from Pharmaceuticals," Southern Economic Journal, Vol. 78 (1): 167-190.

Bradford, D., Kleit, A., Nietert, P, Ornstein, S. 2010. "The Effect of Direct to Consumer Television Advertising on the Timing of Treatment," Economic Inquiry, Vol. 48 (2): 306322.

Dave, D. and Saffer, H. 2012. "Impact of Direct-to-Consumer Advertising on Pharmaceutical Prices and Demand," Southern Economic Journal, Vol. 79 (1): 97-126.

Donohue, J.M., Berndt, E.R., Epstein, A.M., Rosenthal, M.B., Frank, R.G. 2004. "Effects of Pharmaceutical Promotion on Adherence tox Guideline Treatment of Depression." 
Medical Care, 42(12): 1176-1185.

Iizuka, T. 2004. "What Explains the Use of Direct-to-Consumer Advertising of Prescription Drugs?" Journal of Industrial Economics, vol. LII No. 3, p349-379.

Iizuka T. and Jin G. 2007. "Direct to Consumer Advertising and Prescription Choice" The Journal of Industrial Economics, Volume 55, Issue 4, page 771.

Pharma Marketing. 2013. "DTC Not As Dead As We Thought... But Digital Ad Spending Down One-Third!" Available at: http://forums.pharma-mkting.com/showthread.php?p=90385. Accessed November 11, 2013.

Rosenthal M., Berndt E., Donohue J, Epstein A, Frank R. 2003. "Demand Effects of Recent Changes in Prescription Drug Promotion," Frontiers in Health Policy Research, 6(1), pp. 1-26.

Weissman J., Blumenthal D., Silk A, Zapert K, Newman M, Leitman R, Feibelmann, S. 2004. "Physicians Report on Patient Encounters Involving Direct-to-Consumer Advertising," Health Affairs, 28, w4-219.

Wosinska, Marta. 2005. "Direct-to-Consumer Advertising and Therapy Compliance." Journal of Marketing Research, Vol. 42, No. 3, pp. 323-332. 